\title{
LUCRECIA MARTEL E ALBERTINA CARRI: NARRATIVAS FEMININAS SUBJETIVAS NO NUEVO CINE ARGENTINO (NCA)
}

\author{
Lucrecia Martel and Albertina Carri: subjective \\ feminine narratives in the nuevo cine argentino \\ (NCA)
}

Mônica Brincalepe Campo*

\begin{abstract}
RESUMO
Lucrecia Martel e Albertina Carri são duas das principais diretoras do nuevo cine argentino, movimento cinematográfico de meados dos anos 1990 e início do século XXI. Nas obras das diretoras, a subjetividade é desenvolvida como uma característica que sublinha os temas privados, ligados particularmente ao olhar das mulheres sobre as relações familiares, às estruturas sociais existentes e às práticas culturais que as envolvem. Partem, portanto, do particular para uma expressão crítica, afinada e atenta daquilo que as cercam. A ênfase na subjetividade busca compreender como o ponto de vista das narrativas incide sobre a escrita da história e expressa o tempo presente. O uso inventivo da linguagem e possibilidades do audiovisual marcam a produção destas diretoras e constroem suas especificidades enquanto artistas. Em suas obras, destacam-se os temas dos conflitos, tanto aqueles referentes à violência existente no interior da família como também relativos ao trato em sociedade, instigando-nos a pensar sobre a singularidade destas como expressões contemporâneas em nossa história. Neste artigo analisarei dois filmes: Los Rubios, de Albertina Carri (2003), e La mujer sin cabeza, de Lucrecia Martel (2008).
\end{abstract}

Keywords: Lucrecia Martel; Albertina Carri; subjetividade; mulheres.

* Professora no Instituto de História da Universidade Federal de Uberlância (UFU). Email: monicampo10@gmail.com 


\begin{abstract}
Lucrecia Martel and Albertina Carri are two of the most important directors of the nuevo cine argentino (new argentinian cinema), a cinematographic movement starting from the 1990s and enduring through the XXI century. In their works, subjectivity is developed as a feature that underlines private themes, being particu-larly connected to women's outlook on the family relations, social structures and cultural practices that surround them. From a sensitive view on personal matters, they then develop a sharp and attentive critique of their environment. This empha-sis in subjectivity strives to understand how the point of view of the narratives af-fects the writing of history and expresses the present time. Inventive use of lan-guage and audiovisual possibilities mark the production of these directors and construct their specificities as artists. The themes of conflict stand out in their works, both those referring to violence existing inside of families and those relat-ed to daily life in society, instigating the viewers to think about the singularity of those clashes as contemporary expressions in our history. In this article, two mov-ies will be analyzed: Los Rubios, from Albertina Carri (2003), e La mujer sin cabe-za, from Lucrecia Martel (2008).
\end{abstract}

Keywords: Lucrecia Martel; Albertina Carri; subjectivity; women.

Agora, acho que teria sido melhor ser ferida nas pernas ou nos braços, que doesse o corpo. Porque a alma...Dói muito! Svetlana, Aleksiévitch. A guerra não tem rosto de mulher

\title{
Introdução
}

A citação na epígrafe deste artigo foi retirada do livro $A$ guerra não tem rosto de mulher, trabalho da Nobel de literatura em 2005, Aleksiévitch Svetlana. Nesta obra, a escritora articulou uma série de entrevistas nas quais as falas das depoentes são recortadas a alinhavar não a grande guerra, tradicionalmente apresentada nos livros de História Militar ou de História Política - aquela que tem sido sempre narrada pela perspectiva masculina - mas a perspectiva de mulheres, orientada pela subjetividade emotiva das que estiveram ativamente no front do 
conflito. Nos relatos, lemos sobre o cotidiano interrompido, o novo cotidiano construído nas trincheiras, aquele que foi obtido na cumplicidade entre muitos, em que a dedicação à causa (a defesa da URSS e a luta contra os nazistas) e à nação, aparecem orientadas pelas sensibilidades e atenções emocionais que escapam em meio aos depoimentos. Narradas algumas vezes com humor e outras tantas com mágoas, porque muito machucadas - em especial com os anos que seguiram à guerra, quando foram destratadas e silenciadas - as entrevistadas produzem uma polissemia não atentada até então nas narrativas de guerras. É esta atenção ao que diz respeito ao sensível - e às sensibilidades femininas, em particular - que parece emergir nos filmes de Lucrecia Martel e Albertina Carri.

As diretoras nasceram nos anos da ditadura argentina e cresceram sob os efeitos diretos dessa ação e experiência. Não são soldadas do front, como as depoentes do livro de Svetlana, mas sobreviventes (especialmente Albertina), da violência presente cotidianamente naquela sociedade em estado de exceção. Podemos, então, relacionar a obra destas diretoras e a reflexão subjetiva dos espectros que rondam seus cotidianos a essa experiência de violência vivida e seus desdobramentos, que estão presentes, expostos e expressos na linguagem audiovisual que elas compuseram. Desta forma, este artigo busca pensar as obras indicadas como expressão de linguagem da violência vivenciada e manifestada em relatos de subjetividade, ligadas aos sentimentos e às sensibilidades de Albertina Carri e Lucrecia Martel.

\section{Pequenas biografias e características estilísticas das obras das cineastas}

Lucrecia Martel é originalmente da região de Salta, ao norte da Argentina. Originalmente de Buenos Aires, Albertina Carri se mudou para o interior depois do sequestro e desaparecimento de seus 
pais pelas mãos da ditadura. Ela passou a infância na casa de seus tios, no campo. Portanto, ambas as diretoras podem ser percebidas envoltas na cultura dicotômica argentina, em que Civilização e Barbárie (Shumway, 2008) norteiam o modo de se pensar a nação. Elas não são frutos do espaço urbano de centralização política e cultural ao qual associamos os buenairenses, mas sim da experiência do atraso com o qual o campo - ou seja, a região não portenha - é observado. Nas obras desenvolvidas pelas cineastas, elas buscam questionar as relações intrafamiliares nas quais são percebidas a permanente tensão e possível emergência da violência.

Em Martel, os espaços das casas estão pensados de maneira envolvente nas tramas, com enquadramentos parciais, os quais em regra não permitem o engano de uma suposta visão de conjunto de um campo aberto e totalizante. Isso faz com que o espectador sempre esteja alerta sobre a incompreensão do espaço cênico e em permanente suspense com a narrativa que se desenvolve. Já em Carri encontramos o uso de variados artifícios de linguagem, como a animação, o stop motion, entre outras técnicas audiovisuais, ou seja, a exploração de distintos meios de expressão para colocar em questão seus temas.

Se gêneros cinematográficos fossem passíveis de serem atribuídos a estas diretoras (mas como indicações e não como amarras de tipologia), à Lucrecia Martel o suspense que constitui a base dos filmes de terror estaria de boa maneira atendido; já em Albertina Carri, mais que o suspense, a explosão da violência parece escapar por sua obra poderia aproximá-la de algo mais afeito ao explícito do gênero slasher. Assim, a tensão do gênero de terror incide de maneira evidente, mas diferenciada nas diretoras. Se em Lucrecia Martel o suspense com o uso da banda sonora e da parcialidade dos enquadramentos constitui a tensão assombrar o espectador em suas narrativas, em Albertina Carri essa tensão acaba por explodir em violência explícita, que não tem por efeito um apaziguamento de seus espectadores e muito menos um destensionar da trama. 
Outra característica que pode ser ressaltada nas diretoras é que estas carregam uma perspectiva feminista que busca gerar um incômodo reflexivo nos espectadores, conduzidos nas tramas por meio de um ativismo sexuado. Dois tipos de personagens mulheres estão caracterizadas em Martel - as falantes e as introspectivas - sendo ambos os tipos enredados nas tramas familiares da sociedade conservadora. Em Carri, as novas expressões de relações afetivas explodem em tela, constituindo diferentes rearranjos familiares. Em ambas as cineastas encontramos a perspectiva crítica em relação à sociedade, principalmente à família nuclear heteronormativa tradicional, sendo a possibilidade ou não de mudanças um vislumbre tenso de ser obtido. Analisar as percepções sobre a família, a sexualidade, a feminilidade, e observar o específico olhar subjetivo que ambas as diretoras empreendem em suas obras é nosso tema de fundo.

\section{Sensível e sensibilidades - subjetividades femininas}

Afirmar que sejam narrativas subjetivas é compreender a maneira como o entorno familiar é colocado no centro das atenções das diretoras a partir da perspectiva sensível e ligada às sensibilidades desenvolvidas criticamente. Não há fronteira ou limite entre o íntimo, o privado e a questão pública. Tudo se embrenha no limiar $^{1}$ dos comportamentos domesticados e civilizados nas quais as aparências se impõem, mas que escapam às amarras e irrompem em tela, escapando dos séculos de soterramento sob as regras que o processo civilizador ocidental construiu.

As narrativas por elas elaboradas possuem um cunho intimista, com abordagem subjetiva, nas quais o autoquestionamento que

\footnotetext{
1 Como alerta J.-M. Gagnebin, Limiar e Fronteira são conceitos distintos em W. Benjamin, e é esta diferença que pretendo aqui indicar. "O limiar designa, ..., essa zona intermediária que a filosofia ocidental - (...) afeita a oposições demarcadas e claras (masculino/feminino, público/privado, sagrado/profano, etc.), mesmo que haja, em alguns casos, um esforço em dialetizar tais dicotomias. (GAGNEBIN, 2014: 37)
} 
construíram enquanto seres do/no mundo é devedor das experiências vivenciadas. Elas não se furtam a se exporem em permanente indagação sobre o ocorrido, e se colocam em cena como parte ativa e entranhada nas amarras deste lugar de memória presente. Entretanto, tal questionamento ressalta não somente seu próprio pertencer, mas o de todos nós. E este é o incômodo principal a manifestar-se nestas obras: a maneira como o particular e o público foram misturados. O campo privado e o público estão imbricados nestas narrativas, e surgem a provocar em todos nós, espectadores, o reconhecimento de nossa história em comum, onde memórias e agruras pessoais se confundem à história geral, fragmentada e misturada de toda sociedade.

Memória e história não são o mesmo: uma está sempre referente ao presente, pois é permanentemente revivenciada, enquanto a outra é uma construção calcada em procedimentos a partir dos quais sua escrita é erigida. A história deve ser cuidadosamente escrita por meio de procedimentos estabelecidos no campo a partir do qual se organizam discursos e narrativas (Benjamin, 2011). A memória se torna objeto analisado pela história, principalmente no século $\mathrm{XX}$, quando entre tantas atrocidades cometidas se destacou a destruição documental em massa que foi realizada como política de esquecimentos e ocultação por isso a importância que os testemunhos vieram a assumir (Ricouer, 2008). A relação tênue e tensa entre memória e história por vezes confunde, mas deve ser observada e cuidada (Sarlo, 2007). Os filmes realizados são obras relativas às memórias experenciadas das autoras, $\mathrm{e}$ estes afetam a história.

Das características que marcam as obras fílmicas de Martel e de Carri estão a eleição da estética de relato subjetivo com que as cineastas constroem suas tramas (Piedras, 2014), articulando temas privados às questões relativas à política, à sociedade e às diretrizes das práticas culturais da vivência urbana. Seus artefatos estão marcados por cicatrizes das violências cotidianas que não estão curadas, da impotência diante do observado e/ou vivenciado. Destacam-se os temas 
dos conflitos, sejam aqueles referentes à violência existente no interior da família, como também relativos à vida em sociedade. Os espaços público e privado são matéria destas narrativas que compõem de maneira instigante a prática fílmica a que as diretoras se debruçaram, e nos deixam como rastros documentais a transmitir suas experiências auto-reflexivas (Rago, 2014). Por isso, na escrita da história se sente a motivação de elencar tais obras como linguagem a ser analisadas e pensadas (Seixas, 2004). Estas diretoras são os frutos daquilo que foi vivido sob a ditadura argentina, ou, mais contemporaneamente, nas democracias recentes, insipientes e insatisfatórias, em permanente e persistente luta para existirem e permanecerem vivendo nos países latino-americanos.

A elaboração de suas obras passa por este processo de expurgo particular e geral, da necessidade da escrita pessoal, subjetiva, que relata as violências mínimas e máximas do cotidiano. Este cotidiano mesclado do público e do privado, que agora ocupa a tela, é como uma expressão de seus gritos interiores, necessariamente transmitindo o vivido, e proposto aqui, neste artigo, para ser pensado como instigador de escritas de história (Certeau, 1982).

Os filmes produzidos estão no limiar, na borda borrada que ainda não permitiu passar o passado e o arrasta consigo, nos fazendo permanecer nesta zona cinzenta em que o conflito assim como a negociação podem ser investigados. Podemos interpretar e analisar estes filmes como memórias presentes e marcadas pelo passado, estando repletas com os testemunhos de suas diretoras, afinal, como cita Jeanne Marie Gagnebin ao retomar o historiador Michel de Certeau: "A escrita não fala do passado senão para enterrá-lo. Ela é um túmulo no duplo sentido de que, através do mesmo texto, ela honra e elimina" (Gagnebin, 2014: p. 30).

Para a autora, o ato da escrita, da produção e elaboração de uma obra ocorre para: 
(...) enterrar e honrar os mortos, sobretudo se eu for historiador. Escrevi também para enterrar talvez meu próprio passado, para lembrá-lo e, ao mesmo tempo, dele me livrar. Escrevo então para viver o presente. Escrevo, enfim, para me inscrever na linha de uma transmissão intergeracional, a despeito de suas falhas e lacunas. Assim como leio os textos dos mortos e honro os seus nomes no ato imperfeito de minha leitura, também lanço um sinal ao leitor futuro, que talvez nem venha a existir, mas que minha escritura pressupõe. Lanço um sinal sobre o abismo: sinal de que eu vivi e de que vou morrer; e peço ao leitor que me enterre, isto é, que não anule totalmente minha existência, mas saiba reconhecer a fragilidade que une sua vida à minha. Talvez isso ajude a 'viver enquanto mortal e a morrer enquanto vivente”. (Gagenbin, 2014: p 30)

Os filmes de Martel e Carri não encerram a história, porém atuam de forma a marcar um presente redivivo e ainda incômodo em meio às memórias atuantes que arrastam o passado como espectros em seu cotidiano espiralado. Estas obras parecem situadas em um limiar, como a própria Jeanne Marie-Gagnebin descreve o conceito, ao retomar particularmente Walter Benjamin e os estudos a diferenciar fronteira (Grenze) e limiar (Schwelle).

(...) tendemos a usar, como se fossem sinônimos, as palavras 'fronteira', 'limite', e 'limiar', já que todos os termos aludem à separação entre dois domínios do real, muitas vezes opostos. Assim, esquece-se facilmente que o limiar não significa somente a separação, mas também aponta para um lugar e um tempo intermediários e, nesse sentido, indeterminados, que podem, portanto, ter uma extensão variável, mesmo indefinida. (Gagnebin, 2014: p 37).

Nos dizeres de Lucrecia Martel em entrevista sobre o filme $A$ menina santa, "o que constrói uma história, o que a conta, não é uma coisa tão cerebral e direta, é algo bastante emotivo e misterioso" (Barrenha, 2013: p. 198). "A ideia (ao fazer cinema) é ver com quais 
elementos sonoros, com quais elementos verbais, físicos se pode reconstruir uma emoção que está muito fixada na lembrança de alguém, mesmo que não seja essa cena que a pessoa tenha vivido" (entrevista de Lucrecia a HALAC, 2005: 97 - Apud: Barrenha, 2013: p. 108). E como arremata a própria autora Barrenha, encontramos em Martel "o olhar aguçado para o cotidiano, estudos íntimos e minimalistas da vida familiar de classe média no interior argentino e radiografias humanas às quais o espectador reage com o corpo". (Barrenha, 2013: p. 198).

A narrativa fílmica seria então articulada para expressar o emotivo, elaborada em uma estética onde as sensibilidades são o centro da atenção da diretora. A expressão das sensibilidades agenciadas na polissemia dos tratos entre os humanos em sociedade é a expressão máxima das obras realizadas pelas diretoras. Como mulheres, o olhar feminista que imprimem em suas obras não são o fruto restrito de uma característica biológica, mas referidas ao que Judith Butler (2016) chama de precariedade, parcialidade e contingência expressas pela subjetividade. Não se referem a um essencialismo biológico, e sim ao compromisso do porvir, pois se percebem parte da insegurança, da instabilidade do presente, e se pretendem a reivindicação de um devir, de um futuro, a reagir a um passado espectral que persiste no presente.

Para auxiliar a refletir sobre as obras das diretoras, propomos partir da definição elucidada na proposta de Soares e Miranda sobre o conceito de subjetividade em Deleuze e Guattari, como sendo "tudo aquilo que concorre para a produção de um 'si', um modo de existir, um estilo de existência” (Soares e Miranda, 2016: p. 9). O alerta dos autores Soares e Miranda está em perceber que o conceito de subjetividade está interligado à crítica à abordagem estruturalista que foi baseada na afirmação do "ser". ${ }^{2}$

2 Além disso, observam que este conceito deve ser relacionado a outras questões/conceitos, como os de maquínico, agenciamento coletivos e enunciação, para se compreender o processo de produção das subjetividades em meio ao assujeitamento e à singularização do Capitalismo Mundial Integrado. 
A força dos dispositivos capitalistas em submeter e articular na malha de produção de subjetividades organizadas na contemporaneidade não significa a sujeição e a prisão aos ditames indicados, mas seria possível na leitura rizomática da atuação cotidiana assinalar as válvulas de escape, as resistências e as subversões ao cabedal oferecido.

A essa máquina de produção de subjetividade eu oporia a ideia de que é possível desenvolver modos de subjetivação singulares, aquilo que poderíamos chamar de processos de singularização, uma maneira de recusar esses modos de encodificação preestabelecidos, todos esses modos de sensibilidade, modos de relação com o outro, modos de produção, modos de criatividade que produzam uma subjetividade singular. Uma singularização existencial que coincida com um desejo, com um gosto de viver, com uma vontade de construir o mundo no qual nos encontramos, com a instauração de dispositivos para mudar os tipos de sociedade, os tipos de valores que não são os nossos. (GUATARI; ROLNIK, 1999: 16-7, grifo do autor, Apud Soares e Miranda, 2016: p. 13)

Ao escrever sobre as biografias e estilos das cineastas, refleti sobre questões gerais que perpassam seus diversos filmes, mas elegi somente dois, um de cada diretora, Los Rubios e La mujer sin cabeza, para aprofundar a análise neste presente trabalho. Ao me debruçar sobre a perspectiva da subjetividade, reflito sobre a temporalidade expressa que incide para a reflexão do discurso histórico produzido, imerso em tempo presente (Hartog, 2013), mas que parece resistir em escapes de reivindicações e de devires (Rago, 2014).

\section{Perspectiva de análise em Los Rubios, de 2003, e de La mujer sin cabeza, de 2008}




\section{Albertina Carri}

Albertina Carri realizou Los Rubios, documentário que a destacou em 2003, e que desde sua produção surgiu marcado sob o signo da polêmica (Noriega, 2009). O filme foi realizado em uma narrativa contundente e inovadora, sendo marco do cinema documental do novo século. Ele foi construído a partir de diversos recursos de artifícios cinematográficos a expressarem suas dúvidas, mágoas, vazios, lacunas, feridas, os quais, portanto, mergulham em reflexões subjetivas. Carri lança mão de uma atriz para fazer seu alter ego. Ela explora a animação para representar sua imaginação infantil, ficcionalizando e construindo uma maneira de indicar sua compreensão dos trágicos fatos ocorridos quando era criança.

A apresentação dos depoimentos em talking head, os já clássicos testemunhos, foi feita de maneira diferenciada, estes foram deslocados de seu uso convencional de relato oficial e verdadeiro do passado, e ocuparam outro status, pois foram articulados como um discurso oficioso e insatisfatório para as questões que ela queria ver respondidas. $\mathrm{O}$ filme de Carri repercutiu nacional e internacionalmente de maneira incisiva, e afirmou a presença das reflexões íntimas de sua protagonista/diretora como memórias presentes (Bergson, 2011: p. 41).

Para discutir o caráter subjetivo desta obra indico algumas cenas e sequências do filme: em uma delas vemos a atriz Analia Couceyro, que faz o papel de alter ego de Albertina Carri, sentar-se em meio à ilha de edição cercada por computadores e telas de televisores. Os aparelhos reproduzem as entrevistas/depoimentos realizadas com os companheiros dos pais de Albertina Carri e realizadas no convencional sistema de talking heads de documentários e reportagens comuns em nosso cotidiano. De costas a todo esse equipamento, em uma cadeira giratória, a atriz ignora as telas e folheia o livro de sociologia do pai de Albertina, Roberto Carri. Em nenhum momento do filme essas entrevistas são usadas ou apresentadas. 


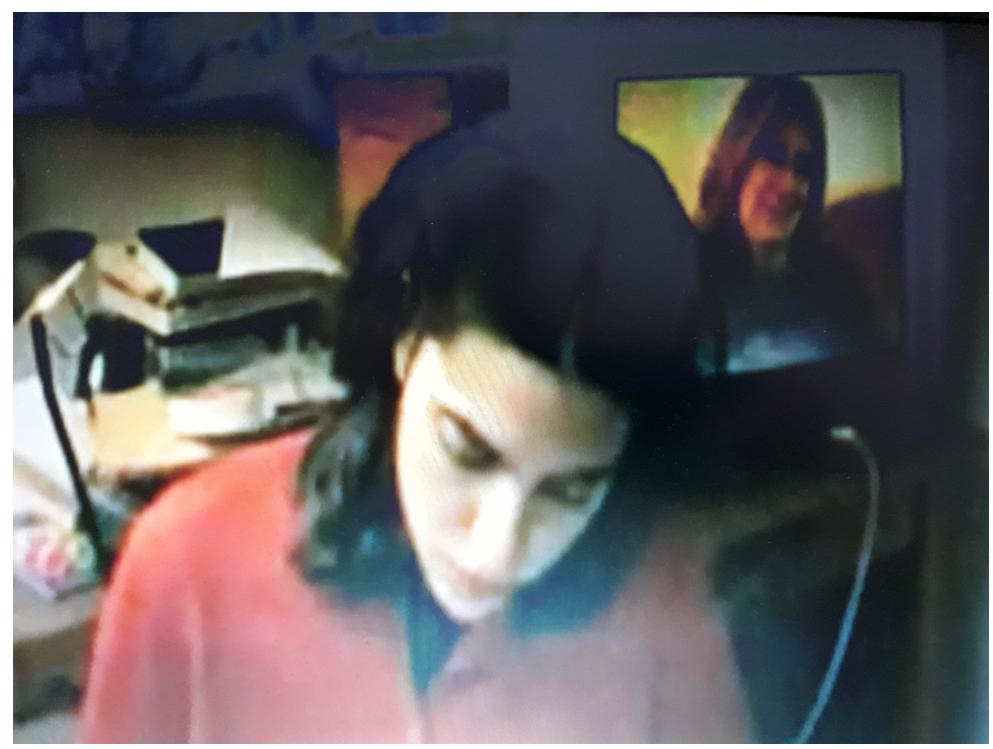

IMAGEM 1 (Los Rubios 11:23 - ilha de edição)

Os relatos e os documentos coletados (fotografias, cartas, exame de dna, etc) são manuseados como peças de um quebra-cabeça incompleto, e não conseguem preencher o vazio da ausência dos pais carregado permanentemente. Não findar a passagem deles em terra, não se despedir (Freud, 2010), não obter os sacramentos finais, levam a este estado limiar que a obra tenta expressar. Voltar-se para o livro de sociologia do pai é recuperar um dos poucos objetos concretos por ele produzido: mesmo que este não tenha por finalidade expressar o afeto a sua filha e seja um texto acadêmico, ele é o resquício de sua personalidade e de sua fala sem intermediários, é a voz que resta. Assim, o filme não é a busca da verdade dos fatos, a investigação dos acontecimentos ocorridos com os pais. Albertina explica em outra sequência, quando recebe a recusa da agência de fomento do governo argentino em financiar o filme (o INCAA), a relação do que pretende 
fazendo o documentário e o conflito com o que esperam e querem que ela faça como filme.

A diretora justifica suas escolhas dizendo que todos (amigos, companheiros, familiares, o governo) constroem relatos que heroificam e santificam seus pais, e que ela os perde em meio a memórias que não são dela. Ela não sabe mais o que é sua própria lembrança e o que vem das imagens construídas pelos demais - seus genitores se tornam diáfanos e afastados da humanidade cotidiana ${ }^{3}$. Recordemos que Albertina era pequena e possuía somente 3 anos quando seus pais foram sequestrados e desaparecidos. Ela mal tem lembranças deles - e aliás, suas memórias estão povoadas por relatos de vários, de outros que com eles conviveram, e não há memórias dela mesma sem que ocorra essa intermediação.

3 A referência à imagem-lembrança de que fala Deleuze, sobre os fantasmas de referência que alimentam a imagem ótico-sonora, parece colaborar para compreensão do que pretende expressar Albertina. 


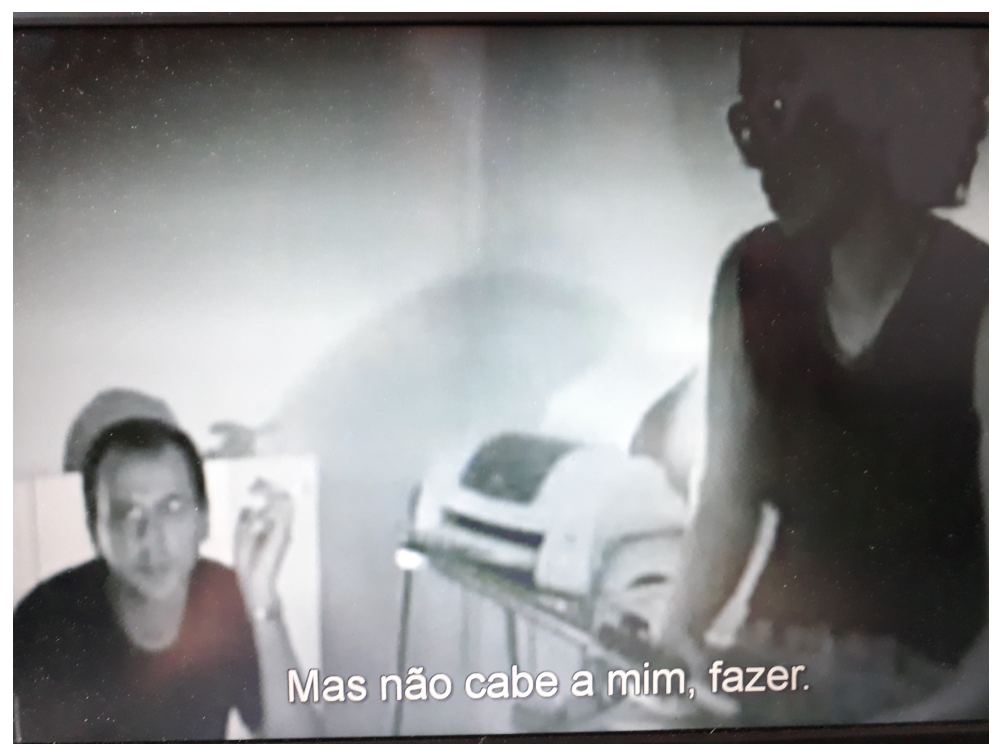

IMAGEM 2 (Los Rubios 27:22 - discussão de equipe e parecer INCAA)

A sequência da ilha de edição é curta e apresenta o deslocar subjetivo, o escape do personagem das amarras memorialísticas que nutrem a escrita da história dos heróis da resistência revolucionária da ditadura argentina. Ali encontramos a filha frustrada e ressentida, a qual não tem como resgatar os afetos perdidos e que procura lidar com as próprias marcas e mágoas. A sobreposição em tela da diretora que dirige a atriz a personificá-la acaba por estabelecer mais ainda a problematização do desdobrar da cena. A mescla das memórias construídas nos diversos depoimentos colhidos ao longo de sua vida marcaram os afetos e nutriram a expressão de sua história. As imagenslembrança estão associadas ao "(...) êxito que permite o fluxo sensóriomotor retomar seu curso temporariamente interrompido".

Quando não nos conseguimos lembrar, o prolongamento sensório-motor fica suspenso, e a imagem atual, a percepção 
ótica presente, não se encadeia nem com uma imagem motora, nem mesmo com uma imagem-lembrança que pudesse restabelecer o contato. Entra antes em relação com elementos autenticamente virtuais, sentimentos de déjà- $v u$ ou de passado 'em geral' (...). Em suma, não é a imagem-lembrança ou o reconhecimento atento que nos dá o justo correlato da imagem ótico-sonora, são antes as confusões de memória e os fracassos do reconhecimento. (Deleuze, 2007: p. 71)

A isso, Deleuze denomina como os mistérios do tempo, "de unir a imagem, o pensamento e a câmera no interior de uma mesma 'subjetividade automática', em oposição à concepção demasiada objetiva dos americanos" (Deleuze, 2007: p. 71-2). Ao buscar escapar dos limites da imagem-ação existentes no cinema norte-americano, os europeus teriam se preocupado em expressar as questões referentes ao fluxo dos pensamentos. Em Los Rubios, a memória e os fluxos de pensamentos são a expressão dos sentimentos que permanecem, e expressados no documentário assumem o caráter de presentificação temporal. O tempo imediato do puro presente norteia a relação de história presentista que emerge na obra. Como uma crônica do viver, a família que se constitui após o mergulho sensorial que se faz ao longo do filme emerge de perucas loiras e está composta pelos integrantes da equipe, tendo sido forjada no encontro daqueles que se elegeram para pertencerem ao grupo que compôs a obra, e também a expressarem um porvir, um devir necessário. É a família formada da empatia de uns com os outros, negociada no limiar e em meio a tantos conflitos, é a família possível e de afetos comuns elegidos. 


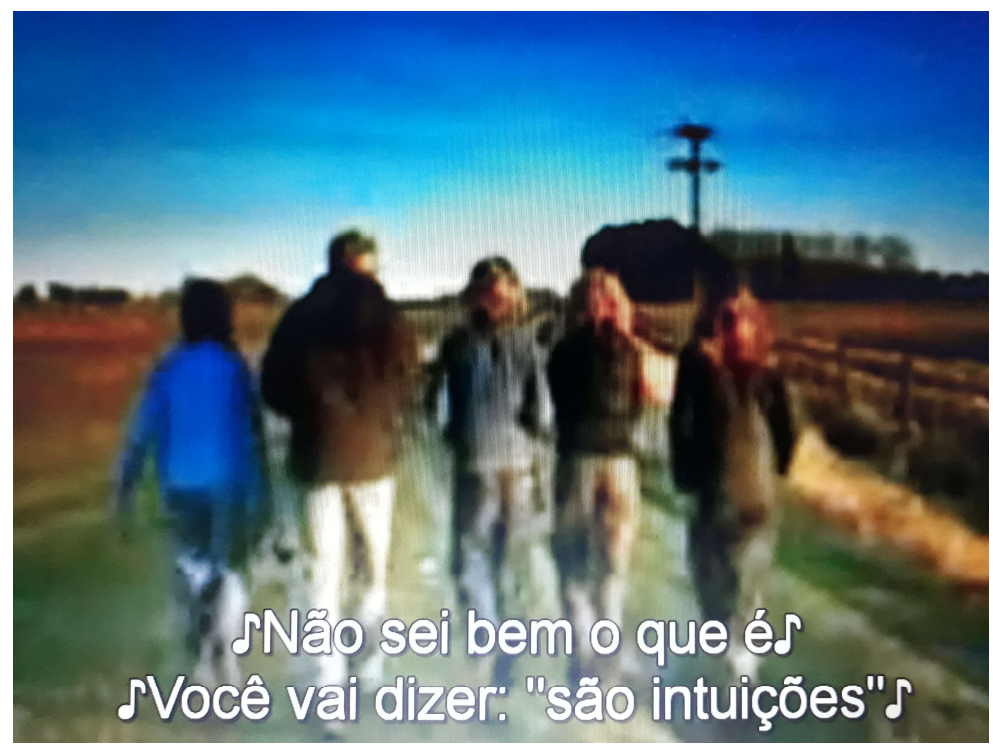

IMAGEM 3 (Los Rubios 1:18:05 - foto seq final)

\section{Lucrecia Martel}

O filme La mujer sin cabeza não é narrado por nenhum dos personagens apresentados em cena. Não há narrador-personagem, mas uma câmera que os observa, bem próxima, em planos fechados, e que assume esta posição de narradora. Dentre os personagens se destaca a protagonista em torno da qual a trama será tecida. Neste caso, a câmera assume uma atitude ainda mais próxima, em closes, e nas poucas vezes em que expande o enquadramento e trabalha a profundidade do campo, mantém este olhar sobre a protagonista. Então, percebemos que a personagem também está a observar seu entorno, mas, apesar de assumir esta posição de observadora, ela nunca é a narradora, pois a ela não é dada a oportunidade do olhar subjetivo ou do ponto de vista 
narrativo. A protagonista sempre está em cena: ouvindo outros que estão agindo em seu redor. ${ }^{4}$

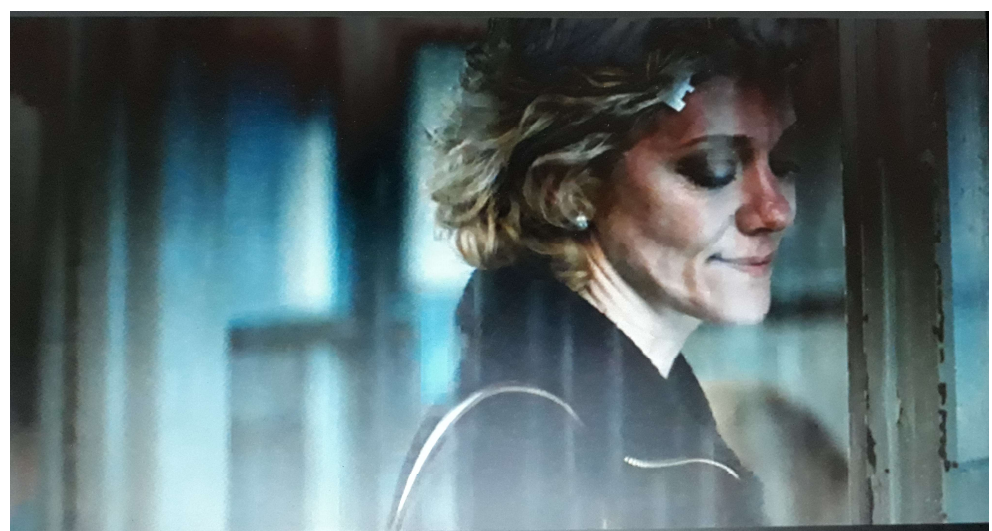

IMAGEM 4 (La mujer sin cabeza 8:26)

Este distanciamento da instância narrativa, forjado principalmente pelos enquadramentos, posição da câmera, planos e ângulos escolhidos, proporciona uma sensação de sufocamento nos espectadores, pois não ocorrem manifestações de aproximação ou de total abandono da trama. Há a permanência próxima, mas sem que ação alguma consiga ou possa intervir nos fatos e acontecimentos. Não há aderência, não há explicação causal, mas se conduz a trama de maneira a supormos o que ocorreu, sem certezas ou indicações cabais, mas indícios que, articulados e somados, tecem uma explicação incerta, mas possível. Assim, não possuímos a origem do olhar - esta é instância narradora onisciente que acompanha a protagonista até o desfecho final, em uma festa em família, em um espaço neutro, fechado entre portas de

${ }^{4}$ A exceção é o prólogo, em que ela está se despedindo de um grupo de mulheres e crianças enquanto três garotos e um cachorro correm e brincam entre si por entre canais. $\mathrm{O}$ encontro com eles será o motivo da trama. Enquanto os garotos disputam entre si a personagem não se encontra no mesmo ambiente, mas em montagem em paralelo em outra situação em simultaneidade das ações. 
vidro. O progressivo afastamento deste olhar observador a cerrá-la em sua bolha de vidro, em que se encerra envolvida pela família, - mas, principalmente, pelos homens que a circundam e falsamente a protegem - é o desfecho enjaulante da trama.

Verô entrou em estado de choque a partir de um acidente que provocou. Em total letargia e distanciamento com o entorno, aparenta estar desmemoriada, pois não age e permanece sem interação, assumindo atitudes de estranhamento. Este comportamento segue até que ela afirma ter atropelado e matado um garoto na estrada. Com a confissão afirmada, os homens que a cercam, seus familiares, passam a construir e articular o que deve ser a história do acidente. Eles constroem uma versão conveniente e, a partir do momento que se faz necessário, apagam os vestígios da história que, com a ausência de indícios documentais, deixará de ser escrita (Ginzburg, 2007). A versão do afogamento do garoto ocorrida em meio à enxurrada se consagrará. Cercada por esses homens, seus parentes protetores, as palavras de Verô são esvaziadas, sua angústia é sufocada e enquadrada na bolha de vidro do salão do hotel em que foi encerrada, ao ser protetoramente controlada e submetida, quando passou a ser cercada por todos. O universo masculino é o do poder: eles têm os contatos, articulam alternativas e saídas, combinam o que deve ser feito; a ela, resta o mesmo que a sua tia, os fantasmas presentes em suas memórias incontroláveis. Verô e sua família são os civilizados, educados e detentores dos fios da história. 


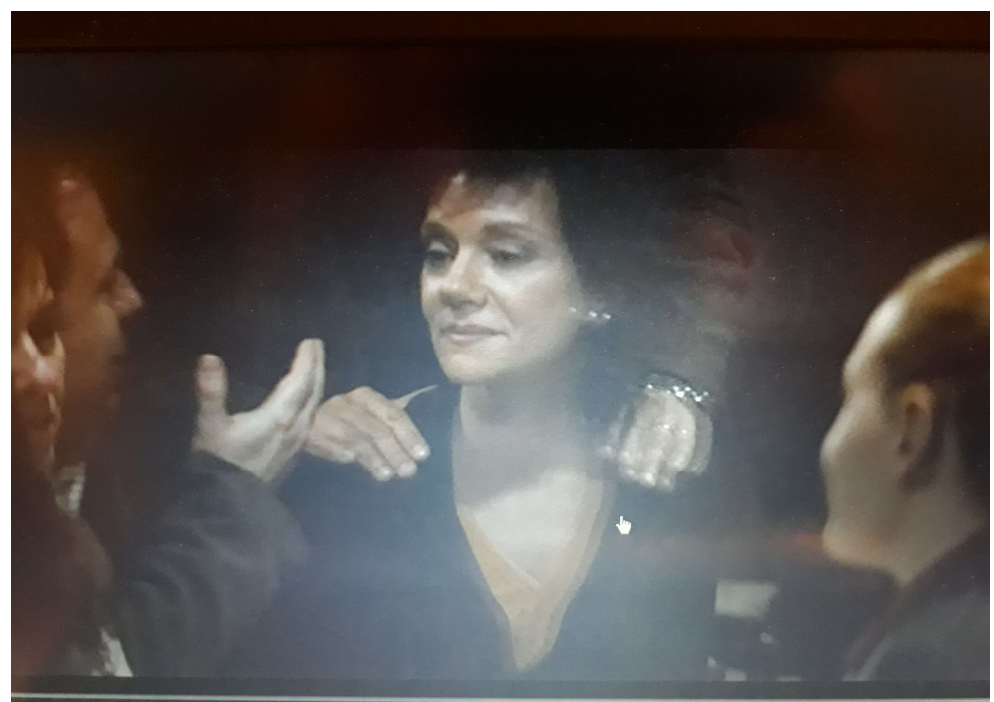

IMAGEM 5 (La mujer sin cabeza - 1:24:07)

\section{Considerações Finais}

As duas cineastas focalizadas neste artigo despontaram como representantes do nuevo cine argentino (NCA) com grande repercussão. A presença de ambas foi percebida como uma nova etapa da Argentina, e deflagrou um movimento de expansão da participação de mulheres na produção cinematográfica a ocuparem as mais diversas posições.

Suas obras cinematográficas seguem o percurso da subjetividade, e expressam o olhar sobre os temas da cultura vivida nesta sociedade em que as amarras e pesos do passado - colonial, na abordagem de Lucrecia Martel, e o ditatorial, na perspectiva envolvida de Albertina Carri - se fazem presentes e atuantes no viver cotidiano. 
Quando nos referimos ao diagnóstico da história política, que fala sobre a oposição permanente entre a ideia de Civilização e Barbárie, em que o comportamento urbano, europeizado, mantém a ideologia de progresso em relação ao atraso da população rural ou suburbana, percebemos que ambas as diretoras expressam os limites e incapacidades deste permanente discurso. Talvez a definição de Sérgio Buarque de Holanda sobre o brasileiro como este sendo o homem cordial possa deixar mais evidente os limites sentidos pelas cineastas e expressos em seus filmes.

Albertina Carri ressente a impotência das escolhas paternas das quais se sente vítima, porque não tem como superar o vazio deixado e não findo, tendo sua vida vilipendiada pelos algozes de seus pais. Sem os corpos, desaparecidos, não há o rito de encerramento, e carrega a ferida permanentemente aberta dos afetos não vivenciados. Há ainda o peso de se descobrir estrangeira no próprio país, pois, Los Rubios, na tradução: Os Loiros, surge como a referência sobre a família de Carri feita pela vizinha entrevistada no subúrbio. Os Carri foram morar na periferia, um aparelho (esconderijo) em que ficaram preparando a resistência à ditadura que se instalara. A vizinha faz referência ao som que era emitido da casa daqueles estranhos vizinhos, a que Carri deduz ser a máquina de escrever do pai. A família Carri, descendente dos italianos estimulados a emigrar para Argentina desde o projeto de branqueamento realizado pelo Estado liderado pelos liberais da geração de 1837 (que chegaram ao poder após a derrota dos federalistas), é ainda estrangeira. Isso ocorre não somente por sua origem geográfica, mas, principalmente, por sua condição social e cultural. A família é diferente, não pertence à população nativa das Américas ou da periferia social/cultural.

O mesmo processo de estranhamento é o que se percebe nos filmes de Lucrecia Martel, e em especial em La mujer sin cabeza, ou traduzindo, A mulher sem cabeça. A personagem central segue cercada e atendida, em interação superficial com os familiares em eventos sociais, isso enquanto uma horda de serviçais nativos permanece no 
suprir das demandas laborais de todos. O acidente com o possível assassinato por atropelamento de um desses serviçais é uma fatalidade do percurso, um incômodo a ser escondido em uma ação saneadora, um fantasma que permanecerá como espectro na família, como diversos outros desde sempre. Entretanto, o mesmo não ocorre à outra mulher vislumbrada durante uma sequência no hospital. Essa outra, uma nativa, está acompanhada de policiais, e será conduzida ao encarceramento sem que nenhum movimento para a libertar seja realizado ou movido. Ou seja, são visíveis as condições sociais, culturais e de poder totalmente diversos essa existente entre ambas.

O homem cordial de Sérgio Buarque de Holanda condiz com este diagnóstico das diretoras, onde o civilizado aparentemente é educado e carrega as intenções de progresso, mas atua autoritariamente e é incapaz de amar o que não é espelho. O povo, a ser salvo pelos pais de Carri, ou a circundar os atônitos descendentes da imigração europeia colonizadora/conquistadora em Martel, permanece no vazio da desconfiança e da marginalidade. Seu lugar pode ser percebido para estas obras realizadas pelas diretoras - e o fato delas serem mulheres talvez permita nesta experiência a empatia de se perceberem em degrau abaixo da hierarquia de comandos, no limiar entre o civilizado de que são parte e o bárbaro do qual são simpáticas, mas ainda assim em um permanente diagnóstico final de fracasso e impotência do atroz encanto de serem argentinas (Freitas Neto, 2008).

\section{Bibliografia}

AGUINIS, M. 2002. O atroz encanto de ser argentino. Trad. Maria Cristina Guimarães Cupertino, Terezinha Martino. São Paulo: Bei Comunicação.

ANSART, P. 2004. "História e Memória dos Ressentimentos". In: BRESCIANI, S. e NAXARA, M. Memória e (res)sentimento: 
indagações sobre uma questão sensível. Campinas/SP: Editora da Unicamp.

BARRENHA, N. C.. 2013. A experiência do cinema de Lucrecia Martel: Resíduos do tempo e sons à beira da piscina. São Paulo: Alameda.

BARRENHA, N. e PIEDRAS, P. 2014. "Silêncios históricos e pessoais". Catálogo da mostra Silêncios históricos e pessoais: Memórias e subjetividade no documentário latino-americano contemporâneo". Caixa Cultural São Paulo, 26 mar. 06 abr.

BENJAMIN, W. "Sobre o conceito de História". In: Magia e técnica, arte e política: ensaios sobre literatura história da cultura. Trad. Sérgio Paulo Rouanet. São Paulo: Brasiliense.

BERGSON, H. 2011. Memória e Vida (textos escolhidos por Gilles Deleuze). Trad. Claudia Berliner; revisão técnica e tradução Bento Prado Neto; 2.ed., SP: Editora WMF Martins Fontes

BUTLER, J. 2016. "Vidas precárias". In: Quadros de guerra: quando a vida é passível de luto?. Trad. Sérgio Lamarão e Arnaldo Marques da Cunha. Rio de Janeiro: Civilização Brasileira.

DELEUZE, G. 2007. A imagem-tempo. São Paulo: Brasiliense (Cinema2).

FREITAS NETO, J. A. 2006. “A formação da nação e o vazio na narrativa argentina: ficção e civilização no século XIX”. Esboços, v. 15, p. 189-204, 2008.

https://periodicos.ufsc.br/index.php/esbocos/article/view/21757976.2008v15n20p189 (consultado em 21/10/2018)

FREUD, S. 2010. "Luto e melancolia" [1917 [1915]). In: Introdução ao narcisismo, ensaios de metapsicologia e outros textos (1914-1916). Obras Completas. Vol. 12. Trad. Paulo César de Souza. São Paulo: Cia. Das Letras, 2010.

GAGNEBIN, J.M. 2014. Limiar, aura e rememoração: Ensaios sobre Walter Benjamin. São Paulo, Ed. 34. 
GINZBURG, C. O fio e os rastros: Verdadeiro, Falso, Fictício. Trad. Rosa Freire d'Aguiar e Eduardo Brandão, SP: Companhia das Letras, 2007.

HARTOG, F. 2013. Regimes de Historicidade: Presentismo e Experiências do Tempo. (vários tradutores). Belo Horizonte: Autêntica. LOPEZ RIERA, Elena. 2009. Albertina Carri. El cine y la furia. Valencia: Ediciones de la Filmoteca (Instituto valenciano del audiovisual Ricardo Muñoz Suay).

LUSNICH, A. L. (editora). 2005. Civilización y barbarie: em el cine argentino y latino-americano. Buenos Aires: Biblos.

NORIEGA, G. Estudio critico sobre Los rubios: Entrevista Albertina Carri. Buenos Aires: Picnic Editorial: Paula Socolovsky.

OUBIÑA, D. 2009. Estudio critico sobre La Ciénaga: Entrevista Lucrecia Martel. Buenos Aires: Picnic Editorial.

RAGO, M. 2013. A aventura de contar-se: Feminismos, escrita de si e invenções da subjetividade. Campinas: Ed. Unicamp.

RICOUER, P. 2007. A memória, a história e o esquecimento. Trad. Alain François (et. al.). Campinas/SP: Ed. Unicamp.

SARLO. B. 2007. Tempo passado: Cultura da memória e guinada subjetiva. Trad. Rosa Freire d'Aguiar. São Paulo: Companhia das Letras.

SEIXAS, J. A. 2004. "Percursos de Memórias em Terras de História: Problemas Atuais". In: BRESCIANI, S. e NAXARA, M. Memória e (res)sentimento: indagações sobre uma questão sensível. Campinas/SP: Editora da Unicamp.

RECEBIDO EM: 01/08/2018 APROVADO EM: 01/10/2018 
